\title{
Social Insurance, Information Revelation and Lack of Commitment
}

\author{
Mikhail Golosov Luigi Iovino \\ Princeton Bocconi
}

First Version: September 2011.

Current Version: November 2012. 


\section{Introduction}

A large literature has considered socially optimal insurance in economies where agents have private information about their needs or skills. One major conclusion, which has proved to be quite robust in different environments, is that incentives can be provided efficiently only by letting inequality in society grow without bounds up to the point where the majority of individuals is close to misery while few lucky are extremely wealthy. This result is, however, unappealing especially when considering that governments are elected by citizens and, thus, they are likely to be replaced before this extreme inequality is realized. Motivated by this observation, the subsequent literature has focused on governments lacking the commitment power to immiserate the majority of its voters.

In general, whether it has commitment power or not, a government that wants to provide its citizens with insurance and incentives will typically need to collect a huge amount of information. All this information, however, may tempt a government that lacks commitment to renege on its past promises and redistribute wealth from lucky individuals to unlucky ones. Virtually all the models in the literature, however, have sidestepped the issue of how information can affect the incentives of the government by making assumptions that essentially guarantee that a deviating government cannot exploit the information collected. ${ }^{1}$

The first to consider the possibility that the government may surprise citizens by exploiting the information collected in the past was Roberts (1984). He considers a model where riskaverse individuals are subject to random shocks. The economy is repeated $T$ times and shocks are fully persistent. A benevolent planner wants to provide insurance to the individuals, but cannot refrain from using the information collected to redistribute resources. Under these assumptions, Roberts derives a very negative result: The only incentive-compatible allocation of this game involves all the citizens reporting the same information to the government which can then offer no insurance.

This paper studies an economy populated by a continuum of citizens subject to privately known random shocks similar to the one studied in Atkeson and Lucas (1992). There is a constant aggregate endowment in each period and a benevolent government wants to provide citizens with insurance against their random shocks. The government offers incentive compatible allocations to the agents in order to learn the realizations of their shocks. The government, however, lacks the ability to commit to a particular allocation and can potentially renege on

\footnotetext{
${ }^{1}$ Farhi-Werning (2011), Yeltekin and Sleet (2011) assume that shocks are uncorrelated over time while Acemoglu, Golosov and Tsyvinski (2011) allow citizens observing a deviation to immediately react so that the government cannot exploit its information.
} 
its promises. Contrary to Roberts (1984), our economy last forever and shocks to individuals are assumed to have different degrees of persistence. We show that persistence of information together with lack of commitment severely hinder the ability of the government to collect information from the agents and, therefore, to provide insurance in equilibrium. The results we obtain, however, are less extreme than those found by Roberts and some insurance can be provided in equilibrium. In particular, we show that the efficient allocation induces some agents - those who have been promised low expected utility - to misreport their shocks with some probability. Misreporting limits the information available to the government and, thus, reduces the temptation to renege on its promises. In other words, when some agents partly misreport their shocks, the government has access to less information which it can use when deviating.

More formally, we consider a continuum of agents with utility at time $t$ given by

$$
\mathbb{E}\left[\sum_{s=0}^{\infty} \beta^{s} \theta_{i, t+s} U\left(c_{i, t+s}\right) \mid \theta_{i}^{t}\right] .
$$

Each individual belongs to a family denoted by $v \in V$. Let $\psi(v)$ denote the cumulative distribution function across families. A benevolent government weights all agents' utilities equally,

$$
\int_{V} \int_{0}^{1} \mathbb{E}\left[\sum_{s=0}^{\infty} \beta^{s} \theta_{i, t+s} U\left(c_{i, t+s}\right) \mid \theta_{i}^{t}\right] d i d \psi(v) .
$$

We follow Chari and Kehoe (1990) and model the strategic interaction as a game between the government and the citizens. The government does not observe the realizations of $\theta_{i}$, but it collects information by having the agents submit a message at the beginning of each period. After observing all the reports, the government allocates consumption to the agents. We assume that the government lacks commitment power and can potentially select allocations that differ from what it promised at the beginning of the period.

We focus on the best equilibrium of this game, that is, the equilibrium allocations that maximize (1). We show that citizens incentivize the government with the threat that they will stop revealing information if they observe a deviation. A government deciding whether to deviate will therefore trade off the possibility of taking advantage of the information accumulated in the past with the threat of receiving uninformative reports in the future. There is a strong incentive to deviate, therefore, whenever (i) the government has accumulated a lot of information and (ii) the value of this information does not decay over time too quickly (that is, shocks have higher persistence). 
We show that, under some conditions, the best equilibrium allocations solve a simple problem where the government maximizes the welfare of each family $v \in V$ separately. We use this result to characterize the best equilibrium and, in particular, we show that agents who have been promised very low lifetime utility will send completely uninformative reports. On the contrary, agents who have been promised higher utility levels send informative messages and, when promised utility is above a certain threshold, they reveal the truth. Providing the government with less information makes a deviation less profitable and ameliorates the lack of commitment problem. 